\title{
Spatial Relationships of Landscape Attributes and Wheat Yield Patterns
}

\author{
H.U. Farid ${ }^{1,}$ A. Bakhsh ${ }^{2}$, N. Ahmad ${ }^{2}$, A. Ahmad ${ }^{3} \&$ A. Farooq ${ }^{4}$ \\ ${ }^{1}$ Ph.D. Student, Department of Irrigation and Drainage, University of Agriculture, Faisalabad, Pakistan \\ ${ }^{2}$ Department of Irrigation and Drainage, University of Agriculture, Faisalabad, Pakistan \\ ${ }^{3}$ Department of Agronomy, University of Agriculture, Faisalabad, Pakistan \\ ${ }^{4}$ Department of Fiber and Textile Technology, University of Agriculture, Faisalabad, Pakistan \\ Correspondence: A. Bakhsh, Department of Irrigation and Drainage, University of Agriculture, Faisalabad, \\ Pakistan. E-mail: bakhsh@uaf.edu.pk
}

\author{
Received: October 19, 2012 Accepted: November 5, 2012 Online Published: December 14, 2012 \\ doi: $10.5539 /$ jas.v5n1p 275 \\ URL: http://dx.doi.org/10.5539/jas.v5n1p275
}

\begin{abstract}
Success of precision farming practices requires knowledge of fields such as soil type, topography, soil nutrients, spatial variability effects, yield patterns and their spatial relationships. A three year (2008-09 to 2010-11) field experimental study was conducted at Postgraduate Agricultural Research Station, University of Agriculture, Faisalabad, Pakistan, to identify the influencing landscape parameters and their spatial distribution, having effects on wheat yield patterns using artificial neural network (ANN) and GIS map overlay techniques. A total of 48 soil samples were collected from top $30 \mathrm{~cm}$ of the soil, before sowing, at center of each grid of $24 \times 67 \mathrm{~m}$ in size along with position data using Global Positioning System receiver (GARMIN, GPS60). Landscape attributes such as elevation, \%sand, \%silt, \%clay, soil electrical conductivity (EC), pH, soil nitrogen (N) and soil phosphorus were included in the analysis. ANN analysis revealed that urea fertilizer treatments, followed by \%sand, \%silt, \% clay, elevation, soil nitrogen and EC were ranked as the most influencing parameters. The yield data, however, were normalized to remove fertilizer treatments effects and then were used in the subsequent analysis. The map overlay analysis showed that the areas having lower elevation, lower soil EC and higher levels of soil $\mathrm{N}$ produced higher yields. Whereas the areas having higher elevation, higher soil EC and moderate soil N produced lower yields, establishing the cause-effect relationships. These results indicated that ANN and GIS techniques were helpful in identifying the influencing parameters affecting wheat yield, which can be managed under precision farming practices.
\end{abstract}

Keywords: precision farming, landscape attributes, ANN, wheat yield, map overlay

\section{Introduction}

The food and fiber requirements of Pakistan are increasing due to its growing population, which has increased to 180 million in 2012 and is likely to double by 2050 (GOP, 2012). To meet demands of this growing population, there is tremendous pressure on the land and water resources of the country (Ali et al., 2011). Whereas agricultural production of the major food crops including wheat in Pakistan is lower when compared with other countries producing wheat. The average wheat yield per hectare in Pakistan is $27 \%$ lower than the world's average wheat yield (Arifullah et al., 2009). This situation needs attention of the scientist and engineers to find the factors responsible for low wheat productivity in the country. Several scientists have reported that topography, climatic conditions, management practices and spatial variability effects within the field are considered as the main factors affecting wheat productivity. Although spatial variability is a natural phenomenon, however, efforts are underway to manage this factor by studying spatial relationships among the landscape attributes and the yield patterns. (Bakhsh et al., 2000; Abbas et al., 2005; Ayoubi et al., 2007; Marques \& Silva, 2008; Begue et al., 2010).

The spatial variability effects in the field may be an outcome of interaction of many complex factors such as topography, soil properties, climatic conditions and management practices (Iqbal et al., 2005; Jung et al., 2006; Piotrowska et al., 2011). Many researchers have reported considerable variations in the soil properties within a field and their corresponding effects on crop yields (Jaynes \& Colvin, 1997; Bakhsh et al., 2000; Zaman \& Schumann, 2006; Bakhsh \& Kanwar, 2008). Similarly, Bakhsh and Kanwar (2005) reported that soil 
characteristics vary from point to point within a field and therefore, have varying nutrients potential in the field. In addition to soil properties, topography also plays an important role in agricultural fields in term of elevation, slope, surface and subsurface hydrology (Dinaburga et al., 2010). Parent et al. (2008) reported that topography affects yield in a number of ways such as affecting redistribution of soil particles, organic matter (OM), soil moisture and nutrients availability. Similarly, several studies have reported spatial variations in the yield as a result of spatial variability, which were most likely to be controlled by soil properties and landscape features (Jaynes \& Colvin, 1997; Mulla \& Schepers, 1997; Piotrowska et al., 2011). The understanding of the cause-effect relationship of the wheat yield patterns and the underlying spatial variability effects can help improve wheat productivity.

To increase wheat yield based on spatial variability effects within the field, there is a need to treat the soils according to their productivity potential. One such strategy has been recognized as precision farming. Precision farming practices are used to identify, analyze and manage spatial variability effects within the field in order to optimize profitability, sustainability and environmental protection (Duffera et al., 2007). To make precision farming a viable practice, there is a need to have better understanding of the functional relationships between soil properties, topography and crop yields. Several techniques have been used to identify influence of the landscape attributes on wheat yield patterns such as crop growth models, statistical techniques, Geographic Information System (GIS) analysis as well as artificial neural network (ANN) approach (Sinclair \& Seligman, 1996; Behera \& Panda, 2009; Bernard \& Yakubu, 2010; Noori et al., 2011). The ANN approach can also be used to find the most influencing parameters affecting wheat yield and predictions can be made based on these identified parameters.

The ANN approach has been applied to almost all areas of engineering and technology (from Agriculture to Space Engineering) with great success (Zhai et al., 2006; Awodele \& Jegede, 2009). ANN modeling mimics the human brains and develops the ability to learn from the real world experimental data (Khazaei et al., 2008; Noori et al., 2011). They can learn the complex relationship (linear or non-linear) and are able to make intelligent predictions on the unseen data (Farooq \& Cherif, 2008; Farooq, 2010). This capability of ANN modeling technique makes it more suitable to predict response of the complex system affected by many factors such as crop growth rates and crop yield in wake of the varying landscape attributes (Solaimani, 2009). GIS has also been used to overlay data layers of landscape attributes identified by various modeling techniques such as ANN to establish the spatial relationships.

To understand spatial variability effects on wheat yield, many researchers have used GIS as a management tool to address these repercussions. A study conducted by Yang et al. (1998) using GIS found that topographic attributes have an influence on the crop yield variability in the Palouse region. Moreover, the effect of soil and topographic attributes on yield variability can be explained well when data layers of these soil attributes are overlaid on the yield data layers. Many researchers have used map overlay analysis to determine the integrated effects of various factors (Hashmi et al., 1995; Diaz et al., 1998). GIS software has ability to generate and overlay various data layers in order to investigate their interaction with each other over space and time domain (Bakhsh et al., 2007).

It is critical to establish the cause-effect relationship for varying wheat yield patterns in the field in order to develop the remedial measures for increasing wheat productivity. Keeping in view the above referred research work, no study has been conducted so far to identify the influencing parameters affecting wheat yield using ANN approach and then overlay these parameters to investigate their spatial relationships. Therefore, this study has been designed with the following specific objectives:

Use artificial neural network (ANN) approach to identify the influencing landscape parameters affecting wheat yield.

Perform map overlay analysis of data layers of the identified attributes from ANN approach to investigate their spatial relationships with wheat yield patterns using GIS software.

\section{Material and Methods}

Field experiments were conducted at Postgraduate Agricultural Research Station (PARS) of the University of Agriculture, Faisalabad, Pakistan, during wheat growing seasons of 2008-09, 2009-10, and 2010-11 to study the effects of urea fertilizer application rates on wheat yield. The study area is located in Rachna Doab (land between river Ravi and Chenab) with coordinates having longitude of $73^{\circ} 0^{\prime} \mathrm{E}$ and latitude of $31^{\circ} 2^{\prime} \mathrm{N}$ (Figure 1). The field has been traditionally under wheat cultivation over the years. The study area is a part of the Indus Plain, which consists of alluvial deposits, brought by the Indus River and its tributaries from the Himalayas. The soils of the study area are predominantly medium to moderately coarse. The soils are generally low in organic matter contents having $\mathrm{pH}$ in the range of 7.0 to 7.9. The climate of the study area touches two extremes with maximum daily summer temperature reaching $48^{\circ} \mathrm{C}$ and winter minimum daily temperature of about $4.8^{\circ} \mathrm{C}$. The mean annual 
temperature is $24^{\circ} \mathrm{C}$ with mean annual maximum of $31.6^{\circ} \mathrm{C}$ and mean annual minimum of $17.6^{\circ} \mathrm{C}$. The average normal precipitation at the study area is $386 \mathrm{~mm}$ (ASP, 2010).

Figure 1 shows location of sampling points in the experimental field of 8 ha in size. The elevation survey of the field was conducted at 48 data points, following a regular grid of $24 \times 67 \mathrm{~m}$ in size using optical surveying dumpy level (Sokkia C330). The highest elevation of $185.9 \mathrm{~m}$, above mean sea level, was found at the east corner of the field whereas the lowest elevation of $185.0 \mathrm{~m}$ was at the west corner of the field, showing slope in the direction from east towards west. A total of 48 soil samples were collected from top $30 \mathrm{~cm}$ of the soil at center of each grid using augers prior to sowing of wheat (Figure 1). These soil samples were sent to the Soil Salinity and Water Testing Laboratory, Ayub Agricultural Research Institute, Faisalabad, for determining percent sand, silt, clay, soil $\mathrm{EC}, \mathrm{pH}$, soil nitrogen and phosphorus. Based on textural analysis, soil of the study area was classified into five classes i.e. clay loam, clayey, sandy clay loam, sandy loam and silt clay loam.

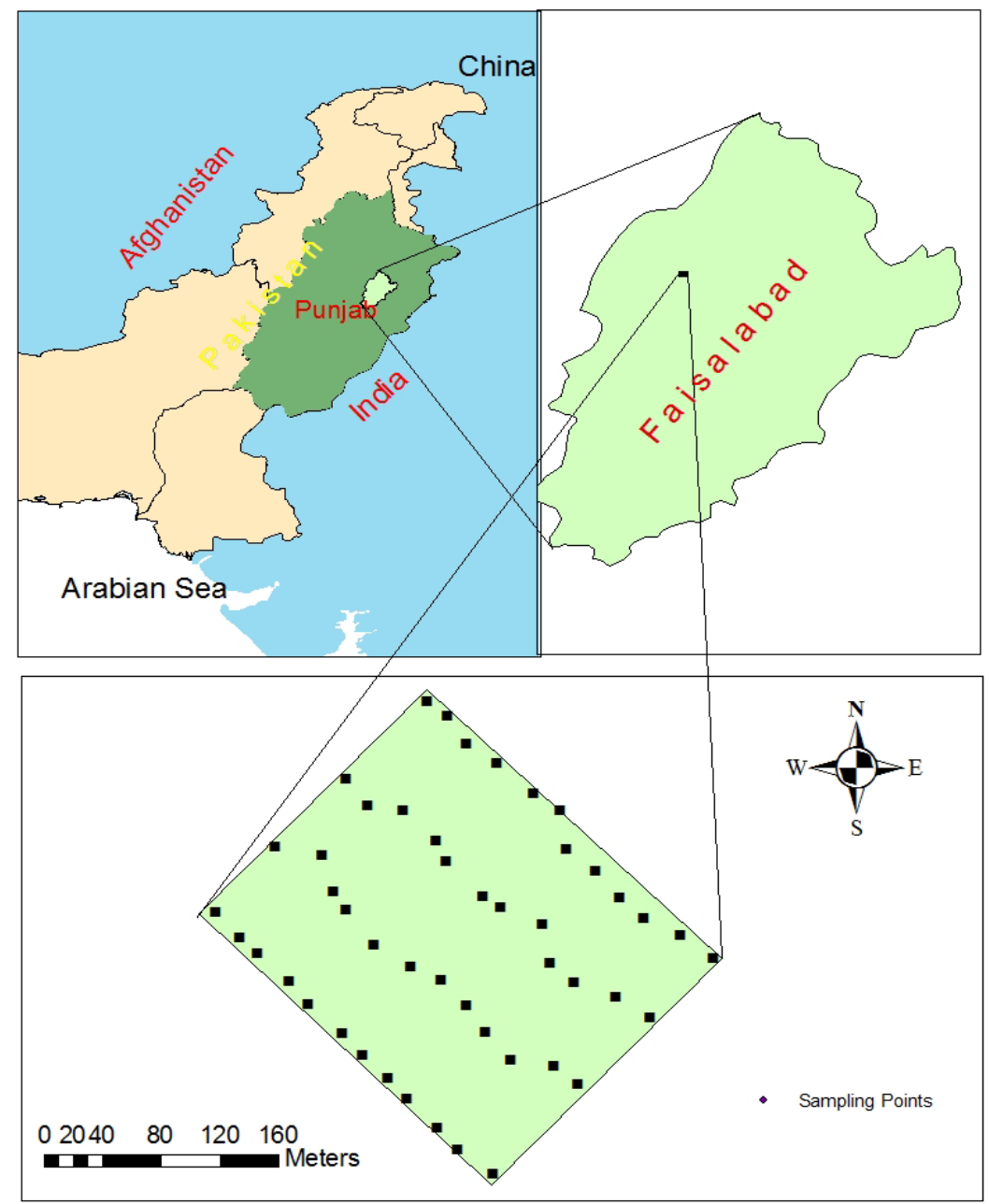

Figure 1. Sampling sites at the study area

\subsection{Management Practices and Yield Data}

Wheat was grown in the field during growing seasons of 2008-09, 2009-10 and 2010-11. The Randomized Complete Block Design was used for experiments on four blocks, each block of 2 ha in size having 12 experimental units in each block. The size of each experimental unit was 24 x $67 \mathrm{~m}$ (0.167 ha). Disc plough and tine cultivar were used for primary and secondary tillage operations, respectively. Seed drill was used for sowing wheat in the rows spaced at $15 \mathrm{~cm}$. Weeds were controlled using herbicide. The complete detail of management activities is given in Table 1. The year-wise urea fertilizer treatments were applied as given below: 
Table 1. Schedule of management activities performed during study period

\begin{tabular}{llll}
\hline Management activities & $2008-09$ & $2009-10$ & $2010-11$ \\
\hline Rouni (pre-sowing irrigation) & Oct 28-30, 2008 & Oct 28-30, 2009 & Oct 21-23, 2010 \\
Land preparation & Nov 11, 2008 & Nov 19, 2009 & Nov 14-15, 2010 \\
Fertilizer application (DAP) & Nov 11, 2008 & Nov 19, 2009 & Nov 15, 2010 \\
Sowing date* & Nov 14, 2008 & Nov 20, 2009 & Nov 15, 2010 \\
$1^{\text {st } \text { Irrigation** }}$ & Dec 06, 2008 & Dec 21, 2009 & Dec 15, 2010 \\
$2^{\text {nd }}$ Irrigation** & Feb 08, 2009 & Feb 17, 2010 & Feb 20, 2011 \\
$3^{\text {rd }}$ Irrigation** & Mar 10, 2009 & Mar 20, 2010 & Mar 20, 2011 \\
Harvesting & Apr 15, 2009 & Apr 14, 2010 & Apr 24, 2011
\end{tabular}

* Seed of wheat, AS-2002 variety, was applied at the rate of $125 \mathrm{~kg} \mathrm{ha}^{-1}$ at row to row spacing of $150 \mathrm{~mm}$.

** Urea fertilizer was applied according to designed treatments just prior to irrigation on the same day.

\section{Treatments for 2008-09}

Treatment $1(\mathrm{~T} 1)=173 \mathrm{~kg}$-urea ha ${ }^{-1}$ in single application with $1^{\text {st }}$ irrigation

Treatment 2 (T2) $=123 \mathrm{~kg}$-urea ha ${ }^{-1}$ in single application with $1^{\text {st }}$ irrigation

Treatment $3(\mathrm{~T} 3)=74 \mathrm{~kg}$-urea $\mathrm{ha}^{-1}$ in single application with $1^{\text {st }}$ irrigation

Treatment 4 (T4)=control, no urea fertilizer was applied

Treatments for 2009-10

Four treatments (T1 to T4) from 2008-09 were repeated during 2009-10 with the following additional treatments:

Treatment $5(\mathrm{~T} 5)=173 \mathrm{~kg}$-urea ha ${ }^{-1} @$ three equal split applications with $1^{\text {st }}, 2^{\text {nd }}$ and $3^{\text {rd }}$ irrigations

Treatment $6(\mathrm{~T} 6)=123 \mathrm{~kg}$-urea ha ${ }^{-1} @$ three equal split applications with $1^{\text {st }}, 2^{\text {nd }}$ and $3^{\text {rd }}$ irrigations

Treatment 7 (T7)=99 kg-urea ha ${ }^{-1} @$ three equal split applications with $1^{\text {st }}, 2^{\text {nd }}$ and $3^{\text {rd }}$ irrigations

Treatment 8 (T8)=296 kg-urea ha ${ }^{-1} @$ three equal split applications with $1^{\text {st }}, 2^{\text {nd }}$ and $3^{\text {rd }}$ irrigations

Treatment 9 (T9)=247 kg-urea ha ${ }^{-1} @$ three equal split applications with $1^{\text {st }}, 2^{\text {nd }}$ and $3^{\text {rd }}$ irrigations

Treatment $10(\mathrm{~T} 10)=198 \mathrm{~kg}$-urea ha ${ }^{-1} @$ three equal split applications with $1^{\text {st }}, 2^{\text {nd }}$ and $3^{\text {rd }}$ irrigations

Treatment 11 (T11)=Humic acid @ 2.47 liter ha ${ }^{-1}$ with $1^{\text {st }}$ irrigation

Treatment 12 (T12)=Humic acid @ 4.94 liter ha ${ }^{-1}$ with $1^{\text {st }}$ irrigation

Treatments for 2010-11

Four Treatments (T1 to T4) from 2008-09 and 2009-10 were repeated during 2010-11 growing season with the following additional treatments:

Treatment 5 (T5)=variable rate of urea fertilizer application based on soil $\mathrm{N}$

Treatment $6(\mathrm{~T} 6)=247 \mathrm{~kg}$-urea ha ${ }^{-1} @$ three equal split applications with $1^{\text {st }}, 2^{\text {nd }}$ and $3^{\text {rd }}$ irrigations

These fertilizer treatments were designed to determine the level of urea fertilizer applications for maximizing the wheat yield. At maturity, wheat was harvested manually and three yield samples of $1 \mathrm{~m}^{2}$ in size each per plot were collected with their position data using Global Positioning System receiver (GARMIN, GPS60). Average of these three samples was considered as yield of the plot. A total of 48 yield samples were collected each year. These yield samples were threshed manually and weight of the wheat grains was adjusted to $15 \%$ moisture contents. The wheat grain and biological yields per unit area were determined. 


\subsection{Artificial Neural Network (ANN) Approach}

ANN modeling approach was applied on three years (2008-09 to 20010-11) experimental data to rank the most influencing parameters affecting wheat grain yield data. A brief description of the ANNs approach is presented here for its better understanding and application in precision agriculture.

The ANN is an empirical modeling approach and can be used to develop empirically based agronomic models. The ANN approach has been used to simulate complex and ill-defined problems. The ANN has gained popularity for its applications where dependency between independent and dependent variables is unknown, which are complex and difficult to be described using mathematical models. This ability of such modeling approach has made it more important in agricultural system. The use of ANN approach has increased due to its ability to deal with non-linearities, interaction and multiple variables. Unlike other statistical models, ANN does not require assumptions about parametric nature of the factors. The ANN has ability to develop the functional relationship between the input-output variables. It has been conventionally used to develop relationship from limited and inconsistent data sets.

\subsection{Standardization of Data}

Standardization of data transforms all the input variables in the same range so that each variable has an equal chance to exert its influence on the output. Thus standardizing the input and target variables makes the training process better behaved by improving the numerical condition of the problem (Srinivasa \& Brion, 2005; Samarasinghe, 2007; Farooq, 2010). Therefore, collected field data were standardized between $0 \& 1$ using the following Equation 1.

$$
P_{n}=\frac{\left(P-P_{\min }\right)}{P_{\max }-P_{\min }}
$$

Where $\mathrm{P}_{\mathrm{n}}$ is the standardized value of input value $\mathrm{P}$ at nth position whereas, $\mathrm{P}_{\min }$ and $\mathrm{P}_{\max }$ are the minimum and maximum values of the variable $P$.

\subsection{Determining the Most Influencing Yield Limiting Parameters}

For this purpose, nine parameters soil EC, soil $\mathrm{pH}$, soil nitrogen, soil phosphorus, percent sand, silt, clay, elevation and applied urea fertilizer) were used as input variables and grain yield was the output variable. The number of hidden neurons in the hidden layers of ANNs model was determined using different combination of 9-k-s-1 architecture, where $k$ and $s$ are number of the hidden neurons in the first and second layers (Figure 2a), respectively, with an increment of three neurons in each step. The best model was selected on basis of the lowest mean absolute error (MAE). Similarly, appropriate selection of the network structure is of vital significance for training of artificial neural networks. The training algorithms influence prediction efficiency of the neural networks. Traditional back propagation neural networks have disadvantage of being slow and getting stuck in the local minimum. Levenberg-Marquardt (LM) technique was used in this study because it is widely accepted and considered as the most efficient and performs better by using an approximation of Newton's method (Farooq, 2010). The LM algorithm is designed to approach the second-order training speed to compute the Hessian Matrix. Although it requires more memory yet it is much faster than the back propagation. In LM technique, the weight basis is computed using the following updated rule (Equation 2).

$$
\Delta W=\left(J^{T} J+\mu I\right)^{-1} J^{T} e
$$

Where $J$ is the Jacobian matrix of derivatives of each error to each weight, $T$ is the scalar and $e$ is the error vector, $I$ is the identity unit matrix and $\mu$ is the scalar value. ANN structure with two hidden layers is shown in Figure 2a.

The cross validation k-fold techniques were used to validate the model. The k-fold means that data were equally divided into $\mathrm{k}$ equal parts. Subsequently $\mathrm{k}$ iterations of training and validation were performed in each iteration. Different fold of data were held out for validation while the remaining k-1 were used for learning. For this study, the data were $10 \%(\mathrm{k}=10)$ cross validated (Figure $2 \mathrm{~b})$. The mean absolute error (MAE) was determined for each test set.

The influencing order of the input parameters was determined by "Predictive importance", which was concerned with the increase in generalization error when an input was omitted from the network. Nine individual neural networks were trained, by omitting one input parameter. The generalization error in terms of MAE was determined for each individual parameter using $10 \%$ cross validation (Figure $2 \mathrm{~b}$ ). These MAEs were compared to determine the influence level of each parameter (Haddad et al., 1997, Noble \& Tribou, 2007, Dai et al., 2011; Lashin \& Din, 2012). 


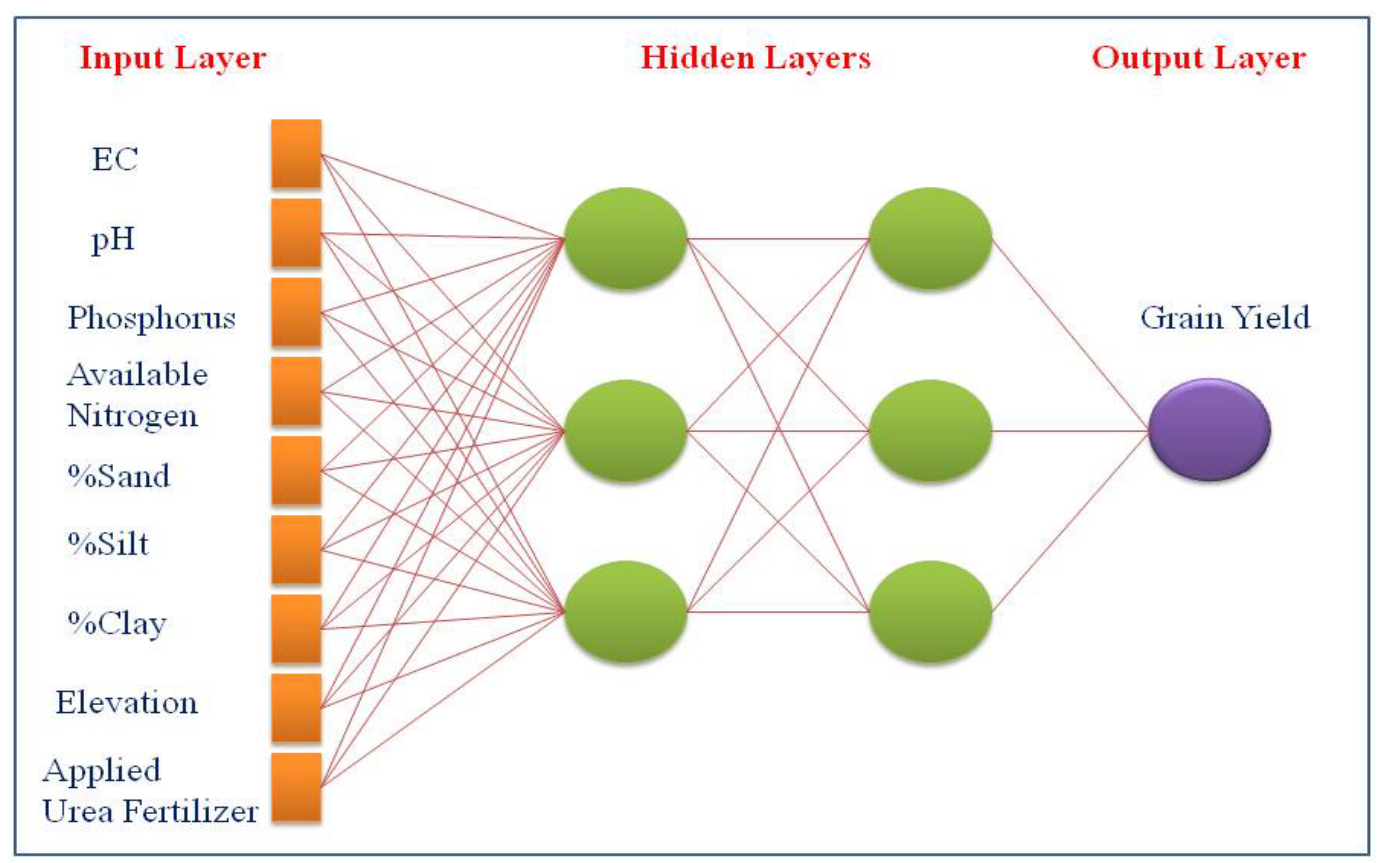

Figure 2a. A feed forward network with two hidden layers

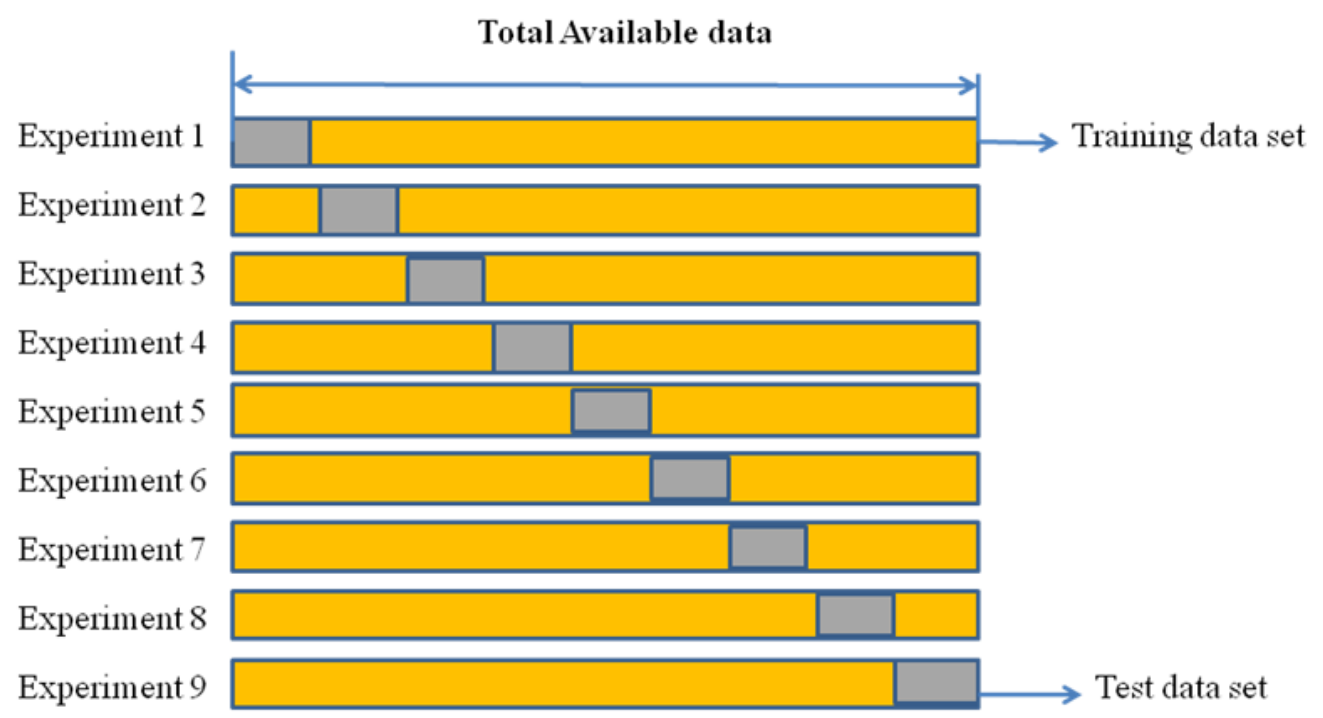

Figure 2b. Cross validation technique for testing neural network performance

\subsection{Data Normalization to Remove Treatment Effects}

Wheat yield data were analyzed using statistical package, Statistix V8.1. It was found that all treatment effects were significant at $5 \%$ level of significance $(\mathrm{P}=0.05)$, which might have suppressed the inherent spatial variability potential of the soil for wheat yield. As the objective was to investigate the spatial variability effects and study the spatial relationships between the soil attributes, topography and the wheat yield. Therefore, it was necessary to remove the treatments effects because of its highly significant effects on the wheat yield for all three years. Therefore wheat yield data for all three years were normalized on treatments basis to remove their effects. An approach (Equation 3), proposed by Jaynes and Hunsaker (1989) was followed for normalizing the yield data:

$$
Z_{j}=\frac{\left(Y j-Y^{\prime}\right)}{s_{j}}
$$


Where $Z_{j}$ is the normalized yield data for $j^{\text {th }}$ treatment, $Y_{j}$ is the measured yield data for treatment $j, Y_{j}^{\prime}$ is median for $\mathrm{j}^{\text {th }}$ treatment and $\mathrm{S}_{\mathrm{j}}$ is interquartile range for data of $\mathrm{j}^{\text {th }}$ treatment. Many researchers have used the same approach for data normalization (Bakhsh et al., 2007, Jaynes et al., 2005, Colvin et al., 1997). As robust estimators, median and interquartile ranges are less affected by the outliers and non-normality on calculation of $Z_{j}(B a k h s h$ et al., 2007; Colvin et al., 1997). The descriptive statistics was calculated using Statistix V8 to check kurtosis and skewness of the data. The normalized yield data were used during subsequent statistical analysis and to prepare the GIS data layers for spatial analysis.

\subsection{GIS Data Layers Preparation}

GIS data layers were prepared using normalized yield data of three years; 2008-09, 2009-10 and 2010-11 using ArcGIS V9.3 software. The ArcGIS Spatial Analyst Tool was used for spatial interpolation with ordinary Kriging to generalize input of the point data. The kriging interpolation technique assumes that distance and direction between the samples reflect point's spatial correlation that can be used to explain variation in the surface. Similar approach has been recommended and was used by different researchers (Tran \& Nguyen, 2008; Bakhsh et al., 2007). Tran and Nguyen (2008) compared several interpolation techniques and recommended use of kriging technique for flat areas. Using ordinary kriging, the best fit spherical model was selected based on the model fitness to the data. The generalized data layer was converted to polygon coverage. The polygon coverage was grouped using different classification techniques (e.g. $\pm 1 \mathrm{SD}$, natural break, quantile, and equal area and equal interval). These data layers were compared and the best classification technique, as used by Nouri et al. (2009), of equal interval was used because this showed better trends of yield variability within the field. Using equal interval classification, polygon data layers were grouped into five classes relatively, designated as very low, low, medium, high and very high.

Similarly, elevation, soil type, soil EC, soil nitrogen, coverages were prepared using the same approach as used for yield coverages. All these coverages were overlaid on three years yield data layers to determine spatial relation between soil properties, topography and yield data.

\section{Results and Discussions}

Table 2. Descriptive statistics of raw and normalized yield data

\begin{tabular}{lcccccc}
\hline \multirow{2}{*}{ Statistics } & \multicolumn{7}{c}{ Grain Yield $\left(\mathrm{kg} \mathrm{ha}^{-1}\right)$} & Normalized Yield \\
\cline { 2 - 6 } & $2008-09$ & $2009-10$ & $2010-11$ & $2008-09$ & $2009-10$ & $2010-11$ \\
\hline $\mathrm{N}$ & 48 & 48 & 48 & 48 & 48 & 48 \\
Mean & 2827 & 3504 & 3699 & 0.091 & 0.213 & 0.104 \\
$\mathrm{SD}$ & 918 & 708 & 903 & 0.792 & 0.928 & 0.911 \\
$\mathrm{SE}$ Mean & 132 & 102 & 130 & 0.114 & 0.134 & 0.131 \\
$\mathrm{CV}$ & 33 & 20 & 24 & 867.000 & 436.180 & 874.800 \\
Minimum & 1200 & 1600 & 1850 & -1.497 & -3.000 & -2.000 \\
$1^{\text {st }}$ Quartile & 1825 & 3200 & 3312 & -0.396 & -0.232 & -0.369 \\
Median & 3000 & 3500 & 3700 & 0.002 & 0.000 & 0.055 \\
$3^{\text {rd }}$ Quartile & 3599 & 4000 & 4250 & 0.752 & 0.794 & 0.594 \\
Interquartile & 1774 & 800 & 937 & 1.150 & 1.030 & 0.970 \\
Maximum & 3899 & 5000 & 5150 & 1.752 & 2.333 & 2.285 \\
Skewness & -0.622 & -0.809 & -0.385 & -0.082 & -0.633 & 0.141 \\
Kurtosis & -1.107 & 1.011 & -0.614 & -0.628 & 2.349 & 0.238 \\
\hline
\end{tabular}

Table 2 shows descriptive statistics for grain yield and normalized yield data collected during three growing seasons of 2008-09, 2009-10 and 2010-11. The wheat grain yield data were found to be skewed negatively for all three years whereas the normalized yield data showed negative skewness only for two years of 2008-09, 2009-10 and were positively skewed for 2010-11. A positive skewness indicates symmetry in distribution with higher data values tailing to the right and negative skewness shows the lower values tailing to the left (Kobayashi et al., 2012). Similarly the interquartile range of wheat grain yield for growing season of 2008-09 was higher compared with those for 2009-10 and 2010-11. The coefficient of variation (CV) of grain yield ranged from $20 \%$ in $2009-10$ to $33 \%$ 
in 2008-09 showing temporal variability in wheat yield data over the years. Statistical analysis revealed that treatment means of wheat yield data were found to be significantly different at $5 \%$ significance level $(\mathrm{P}=0.05)$ over the years. The treatment means of wheat yield were found to be increasing over the years (Table 2). The increase in wheat yields may be attributed to addition of continuous application of fertilizer treatments and favorable climatic conditions. The rainfall, however, varied from year to year. The growing seasons of 2008-09 received rainfall of $83.2 \mathrm{~mm}$ whereas the growing seasons of $2009-10$ and $2010-11$ had rainfall of $23.5 \mathrm{~mm}$, and $48.3 \mathrm{~mm}$, respectively.

Table 3. Descriptive statistics of soil properties

\begin{tabular}{lcccccccc}
\hline Statistics & $\mathrm{pH}$ & $\mathrm{EC}\left(\mathrm{dS} \mathrm{m}^{-1}\right)$ & Soil N (\%) & Soil P $(\mathrm{ppm})$ & Sand (\%) & Silt (\%) & Clay (\%) & Elevation $(\mathrm{m})$ \\
\hline $\mathrm{N}$ & 48 & 48 & 48 & 48 & 48 & 48 & 48 & 48 \\
Mean & 8.462 & 0.578 & 0.028 & 4.786 & 47.271 & 31.229 & 21.500 & 185.730 \\
$\mathrm{SD}$ & 0.299 & 0.328 & 0.006 & 4.131 & 11.851 & 6.895 & 8.158 & 0.174 \\
SE Mean & 0.043 & 0.047 & 0.001 & 0.596 & 1.711 & 0.995 & 1.177 & 0.025 \\
$\mathrm{C} . \mathrm{V}$. & 3.537 & 56.743 & 24.253 & 86.298 & 25.071 & 22.079 & 37.944 & 0.094 \\
Minimum & 7.800 & 0.170 & 0.015 & 0.000 & 20.000 & 12.000 & 10.000 & 185.000 \\
Ist Quartile & 8.225 & 0.402 & 0.026 & 2.532 & 48.000 & 29.250 & 16.250 & 185.640 \\
Median & 8.500 & 0.500 & 0.026 & 3.990 & 50.000 & 30.500 & 18.500 & 185.750 \\
$3^{\text {rd }}$ Quartile & 8.700 & 0.692 & 0.033 & 5.820 & 54.000 & 35.000 & 22.000 & 185.860 \\
Maximum & 9.000 & 2.300 & 0.039 & 22.940 & 68.000 & 50.000 & 45.000 & 185.960 \\
Skewness & -0.522 & 3.191 & 0.154 & 2.394 & -0.956 & -0.476 & 1.286 & -1.677 \\
Kurtosis & -0.723 & 14.009 & -0.678 & 7.610 & -0.052 & 2.175 & 0.788 & 4.690 \\
\hline
\end{tabular}

Table 3 shows descriptive statistics for soil physical and chemical properties, such as mean, standard deviation, variance, standard error of mean, CV, minimum, maximum, skewness and kurtosis. Large differences were found between minimum and maximum values indicating variation in the soil properties. The $\mathrm{pH}, \%$ sand, \%silt and elevation were found to be skewed negatively. The CV values for EC, soil nitrogen, soil phosphorus, \%sand, \%silt and $\%$ clay were found to be more than $22 \%$. The smallest CV was found as 0.09 for elevation, and the highest CVs were observed for soil phosphorus (86.30) and EC (56.74) indicating spatial variability effects. Similar findings have been reported regarding CV of soil EC (57 for top soil) by Cemek et al. (2007). The CV of soil EC has been found to be higher than those of the other soil properties for each soil depth in the field as reported by Gokalp et al. (2010). The higher values of CV for soil parameters may be associated with spatial variability effects of the experimental fields.

The parameters that might have accounted for yield variability were identified using ANN approach. Three years of wheat yield, fertilizer treatments and landscape attributes data were subjected to neural network, 124 datasets were used for training and unseen 20 datasets were used for ANN model evaluation. The number of hidden layers, number of neurons per hidden layer, learning rate, momentum rate, maximum epoch and stopping error were determined by varying different combinations of these network parameters. The optimized network parameters are given in Table 4. The performance of neural network was first checked using "hold out method" on randomly selected data set of 20 values, which showed mean absolute error (MAE) of $9.48 \%$ (Table 5).

The most influencing parameters were found using the predictive importance technique. Table 5 shows MAE resulted from predictive importance technique. The highest MAE difference of $9.33 \%$ was observed in absence of urea fertilizer application and the original MAE increased to $18.81 \%$. This showed level of influence of urea fertilizer on the wheat yield. The second most influencing parameter was \%sand having MAE difference of $0.93 \%$. Similarly, MAE difference for the remaining seven parameters of \%silt, \%clay, elevation, soil nitrogen $(\mathrm{N})$, EC, soil phosphorus $(\mathrm{P})$ and $\mathrm{pH}$ with their influencing order are given in Table 5. These results showed that the applied urea fertilizer, followed by \%sand, \%silt, \% clay, elevation, soil nitrogen and EC showed MAE difference of more than 0.40 , indicating the order and magnitude regarding influence of the landscape attributes on the wheat yield. Although soil phosphorus had very close MAE of 0.39 . 
Table 4. Neural network parameters

\begin{tabular}{lc}
\hline Network parameters & \\
\hline Number of neurons in the input layers & 9.00 \\
Number of neurons in the first hidden layers & 3.00 \\
Number of neurons in the second hidden layers & 3.00 \\
Number of neurons in the output layers & 1.00 \\
Learning rate & 0.80 \\
Momentum rate & 0.30 \\
Maximum epoch & 200.00 \\
Stopping error & 0.01 \\
\hline
\end{tabular}

Table 5. Influencing order of landscape attributes using ANN analysis

\begin{tabular}{lcccc}
\hline Parameters* & Units & Rank & MAE** $(\%)$ & $\begin{array}{c}\text { Error Difference } \\
(\%)\end{array}$ \\
\hline Original & - & - & 09.48 & - \\
Fertilizer applied & $\mathrm{kg} \mathrm{ha}^{-1}$ & 1 & 18.81 & 9.33 \\
Sand & $\%$ & 2 & 10.41 & 0.93 \\
Silt & $\%$ & 3 & 10.09 & 0.61 \\
Clay & $\%$ & 4 & 10.04 & 0.56 \\
Elevation & $\mathrm{m}$ & 5 & 10.02 & 0.54 \\
Soil nitrogen (N) & $\%$ & 6 & 09.99 & 0.51 \\
Electrical Conductivity (EC) & $\mathrm{dS} \mathrm{m}{ }^{-1}$ & 7 & 09.94 & 0.45 \\
Phosphorus (P) & $\mathrm{ppm}$ & 8 & 09.88 & 0.39 \\
pH & & 9 & 09.58 & 0.09 \\
\hline
\end{tabular}

*Parameters were selected having error difference $>0.40$;**MAE: Mean Absolute Error.

\subsection{GIS Data Layers Analysis}

GIS data layers for soil type, elevation, soil EC and soil nitrogen show spatial relationships with each other (Figures 3 to 6). The patches of clay loam and clayey soils were found in east corner of the field whereas clayey soil was also visible in central west part of the field. Mostly areas of experimental field had sandy clay loam soils. The sandy loam soil was observed at north corner and along east south border of the field (Figure 3). The elevation contours showed that the highest to lowest elevation contours were running from east to west of the field (Figure 4). The soil EC data layer (Figure 5) shows that east corner has relatively very high soil EC values (1.883-2.290 dS m$~^{-1}$ ) whereas north and south corners have very low EC values $\left(0.179-0.805 \mathrm{dS} \mathrm{m}^{-1}\right)$. Most of the area having low EC values ranged from 0.805 to $1.031 \mathrm{dS} \mathrm{m}^{-1}$ and was in western part of the field. The area of very high EC values was surrounded by two strips of medium EC values (1.03-1.46 $\mathrm{dS} \mathrm{m}^{-1}$ ) and high range of EC value (1.46-1.88 $\left.\mathrm{dS} \mathrm{m}^{-1}\right)$. Similarly, Figure 6 shows status of soil nitrogen in the field. Careful analysis of the soil nitrogen data layer shows that relatively very high class of soil nitrogen ranging from 0.031 to $0.034 \%$ was found in west corner of the field whereas very lower class of soil nitrogen ranging from 0.019 to $0.022 \%$ and low class from 0.022 to $0.025 \%$ soil nitrogen was found at north corner of the field. Most of the field having high values of soil nitrogen ranging from 0.028 to $0.031 \%$ was in east south part of the field. The medium range from $0.025-0.028 \%$ of soil nitrogen was mostly found in the central part of the field.

The spatial analysis showed positive relationship between soil EC and elevation, i.e. the lower elevation, low pattern of soil EC values and higher soil nitrogen contents were observed in the western part of the field. Similarly, significant relationship was observed between soil type and soil EC. The clayey soil has higher EC in eastern corner of the field. It was reported that clay soil has more soil EC than that of sandy loam and sandy clay loam soil 
(Lithourgidis et al., 2006). The sandy loam soil has lower EC values which may be due to higher infiltration rate of this type of soil. The sandy loam soil and very low EC value polygons in north corner of the field resemble with each other showing their spatial relationships. Correlation matrix also showed significant relationship between soils EC, soil nitrogen and soil type. The correlation matrix showed significant negative relationship between soil $\mathrm{EC}$ and sand. The significant positive relationships were observed for soil nitrogen, clay and silt fraction with the soil EC (Table 6). These relationships between landscape attributes can be related to spatial characteristics of these parameters.

The normalized yield data layer (Figure 7) for growing season of 2008-09 shows higher yield in western part of the field and small part of high yield at north eastern corner of the field. Most of the area has medium range of yield. Small part of the lowest (very low and low) yield was found in south-eastern part of the field whereas some part of the low yield was in the north side and some in east western part of the field (Figure 7). The normalized yield data layers for 2009-10 and 2010-11 show that higher (high and very high) yield area was found in west southern part of field and small area of high yield in northern side. Similar to that of 2008-09, most of the areas have medium yield for both of growing seasons of 2009-10 and 2010-11. The lowest yields (classified as very low and low) for growing season of 2009-10 and 2010-11 were found in northern and eastern parts of the field whereas some part of the low yield for 2010-11 occurred in center of the field (Figures 8 and 9).

The relationship between landscapes attributes and normalized yield data was also investigated by developing correlation matrix (Table 6). It was observed that elevation showed significant negative relationship $(\mathrm{r}=-0.279)$ with yield of 2008-09 (Yld09) and non-significant negative relationship ( $\mathrm{r}=-0.177$ and $\mathrm{r}=-0.003)$ with yield of 2009-10 (Yld10) and yield of 2010-11 (Yld11). The \%clay showed significant positive relationship ( $\mathrm{r}=0.240$ and $0.248)$ with Yld10 and Yld11 and non-significant positive relationship ( $\mathrm{r}=0.104)$ with Yld09. The soil EC showed non-significant negative relationship and soil nitrogen and \%sand showed non-significant positive relationship with yield data of all the three growing seasons (Table 6). Similar relationships between landscapes attributes and normalized yield data have been reported by different researchers (Lund et al., 1999; Bakhsh et al., 2000; Lithourgidis et al., 2006; Gokalp et al., 2010).

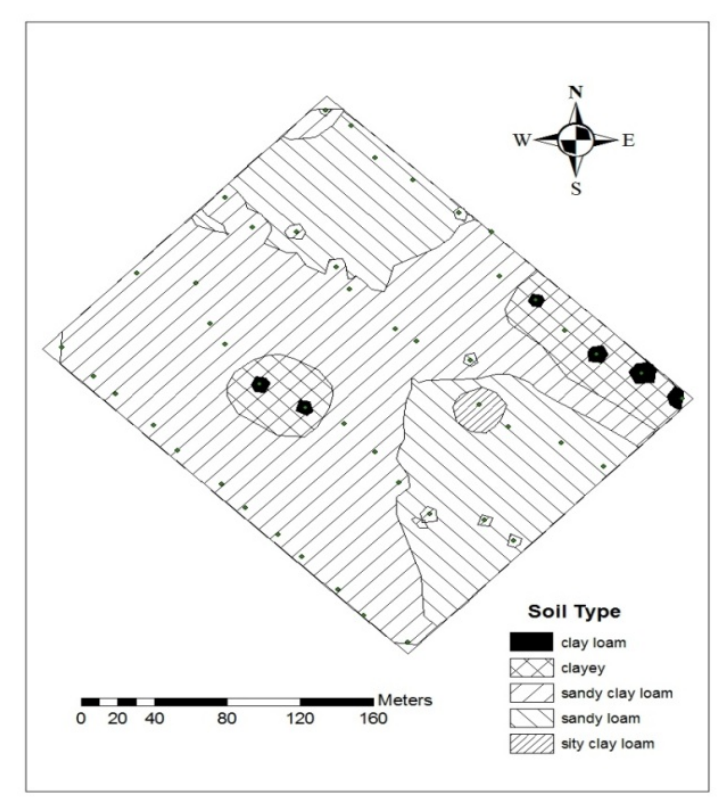

Figure 3. Soil types of the study area

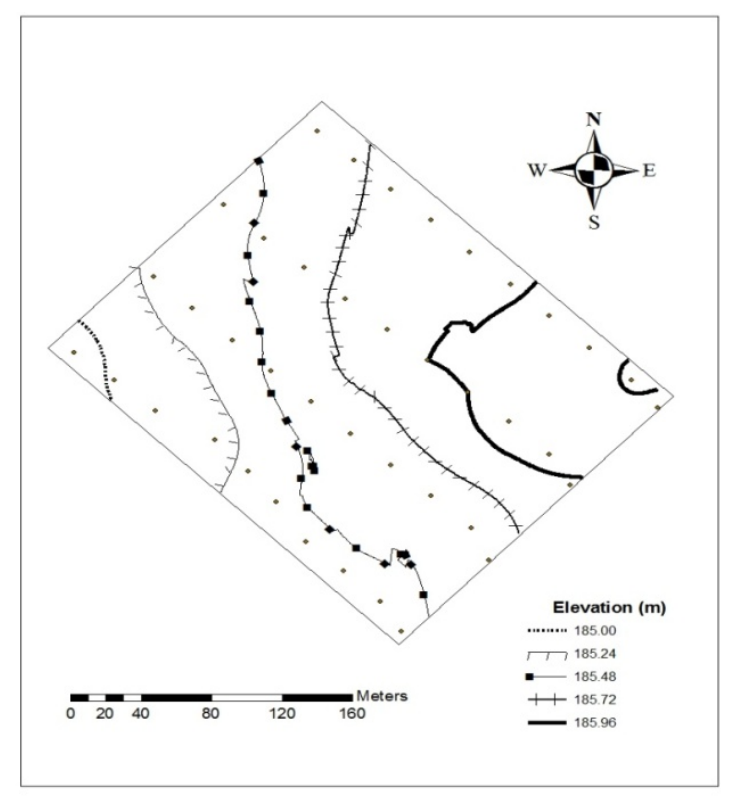

Figure 4. Elevation contours at the study area 


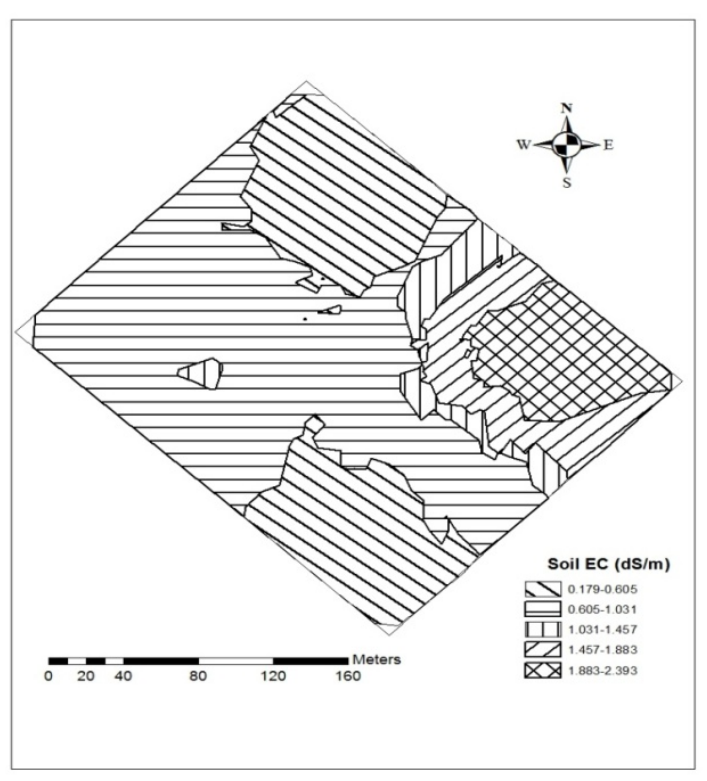

Figure 5. Map of soil EC

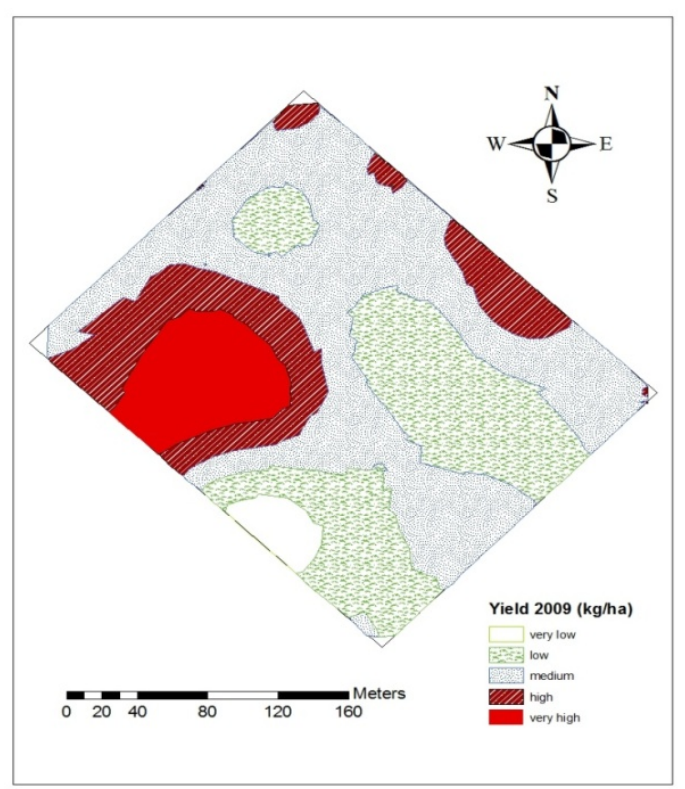

Figure 7. Map of normalized yield data for 2008-09 growing season

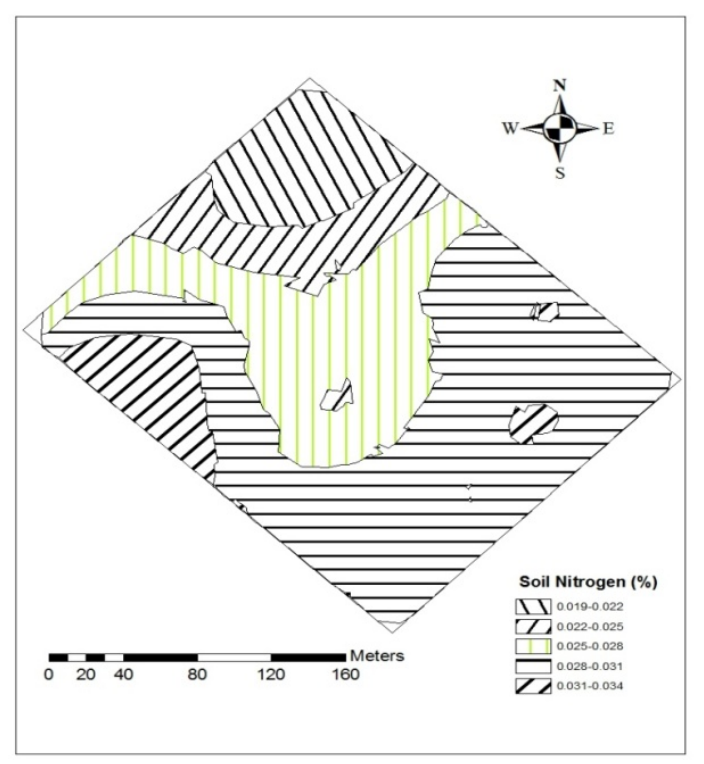

Figure 6. Map of soil nitrogen

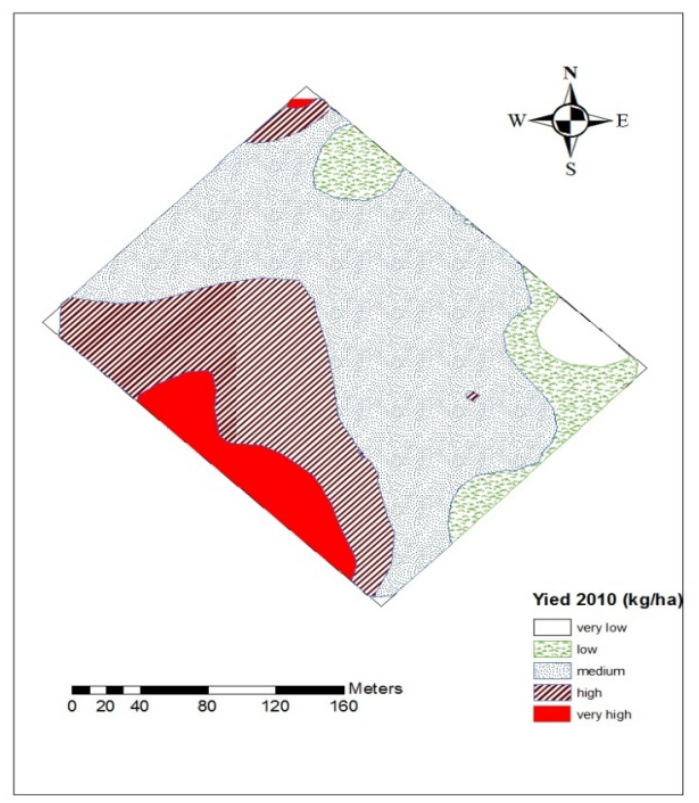

Figure 8. Map of normalized yield data for 2009-10 growing season 


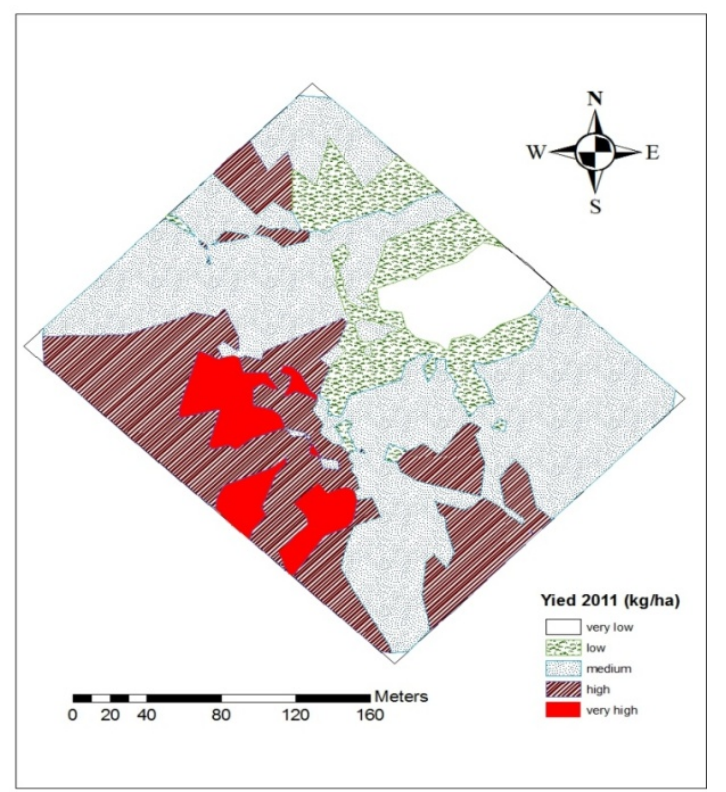

Figure 9. Map of normalized yield data for 2010-11 growing season

Table 6. Correlation matrix of landscapes attributes selected during ANN analysis and normalized yield data

\begin{tabular}{lllllllll}
\hline & Yld09 & Yld10 & Yld11 & EC (dS/m) & Soil nitrogen (\%) & Sand (\%) & Clay (\%) & Silt (\%) \\
\hline Yld10 & -0.038 & & & & & & & \\
Yld11 & -0.172 & -0.066 & & & & & & \\
EC (dS/m) & -0.135 & -0.193 & -0.047 & & & & & \\
Soil nitrogen (\%) & 0.196 & 0.004 & 0.024 & $0.328^{*}$ & & & & \\
Sand (\%) & 0.007 & 0.019 & 0.012 & $-0.502^{* *}$ & -0.136 & & & \\
Clay (\%) & 0.104 & $0.240^{*}$ & $-0.248^{*}$ & $0.460^{*}$ & $0.327^{*}$ & $0.743^{* *}$ & & \\
Silt (\%) & -0.097 & $-0.231^{*}$ & 0.023 & $0.341^{*}$ & -0.080 & $-0.825^{* *}$ & $0.234^{*}$ & \\
Elevation (m) & $-0.279^{*}$ & -0.177 & -0.003 & -0.045 & -0.232 & -0.187 & -0.134 & $0.385^{*}$ \\
\hline
\end{tabular}

*Significant at $\mathrm{P}=0.05$; ** Highly significant at $\mathrm{P}=0.01$; EC: Soil Electrical Conductivity $(\mathrm{dS} / \mathrm{m})$; Yld09: Normalized Yield for Growing Season of 2008-09; Yld10: Normalized Yield for Growing Season of 2009-10; Yld11: Normalized Yield for Growing Seasons of 2010-11

\subsection{Map Overlay Analysis}

The map overlay analysis for normalized yields data layers of 2008-09, 2009-10, 2010-11 and soil type show spatial relationship between yield and soil type (Figures 10a, b, c). The areas having very high yields consistently occurred in the area having sandy clay loam and clayey soil in western part of the field for all three years. Very low yield was observed in area of sandy clay loam in south-western and eastern parts of the field for growing season of 2008-09 and 2010-11, respectively. Whereas very low yield for growing season of 2009-10 was observed in the zone of clayey soil, in eastern corner of the field. This was probably due to lower growing season rainfall of $23 \mathrm{~mm}$ for 2009-10 as compared to the growing season rainfall of 86 and $48 \mathrm{~mm}$ for 2008-09 and 2010-11, respectively. It has been reported that clayey soil can store higher amount of soil moisture over longer period of time due to its higher water holding capacity (Lithourgidis et al., 2006). This analysis also shows that some parts of high yield areas were observed in the zone of sandy loam soil, in northern and southern parts of the field, for growing season of 2010-11. This may be due to high rainfall of $48 \mathrm{~mm}$ during critical period of crop growth from February to April because sandy loam soil is affected by the rainfall at critical stage of the crop growth period (Lithourgidis et al., 2006). It was also observed that the areas having higher grain yield were not consistent over the years showing a temporal variability. The map overlay analysis of the normalized yield and elevation data for growing seasons of 2008-09, 2009-10 and 2010-11 show spatial relationships (Figures 11a, b, c). Elevation is an important attribute influencing the soil moisture movements and storage in the soil and its availability to the plants (Bakhsh et al., 
2000). Careful analysis shows that the areas having higher yield were found in west-southern part of the field and seem to be influenced by topography of the field. The elevation contours show that the areas in western part were at lower elevation and may have more soil moisture availability during the crop growing season (Figures 11a, b, c). The lower yield area for 2009-10 and 2010-11 were near eastern part of the field, which was not consistent as that of 2008-09. Medium yield was observed in central part of the field covering more area.

The map overlay analysis of soil EC and normalized yield data of three year shows the areas having higher yield occurred in parts of the field having low range of soil EC (Figures 12a, b, c). Similarly, the normalized yield data layers show the lowest yield in eastern part of the field having the highest soil EC (Figure 12b). The map overlay analysis for growing season of 2010-11 shows very low yield in the region having higher soil EC (Figure 12c). This shows that high and very high designated classes of soil EC have affected the wheat yield pattern. Similar relationship between soil EC and crop yield data have been reported by Lund et al. (1999). The map overlay analysis (Figures 13a, b, c) of soil nitrogen and yields of 2008-09, 2009-10, 2010-11 showed positive relationships. The area having higher yield relates to the area having higher soil nitrogen in north-southern part of the field. Medium yield was found in the medium and lower area of the soil nitrogen.

These results show spatial relationship between soil attributes of soil type, elevation, soil EC and grain yield for all three years. Overall, soil type, lower elevation, lower soil EC and higher level of soil nitrogen showed higher yield in the field. These results also indicate that these soil attributes can also be used to classify the study area into subunits for applying site specific agriculture inputs in precision agriculture.
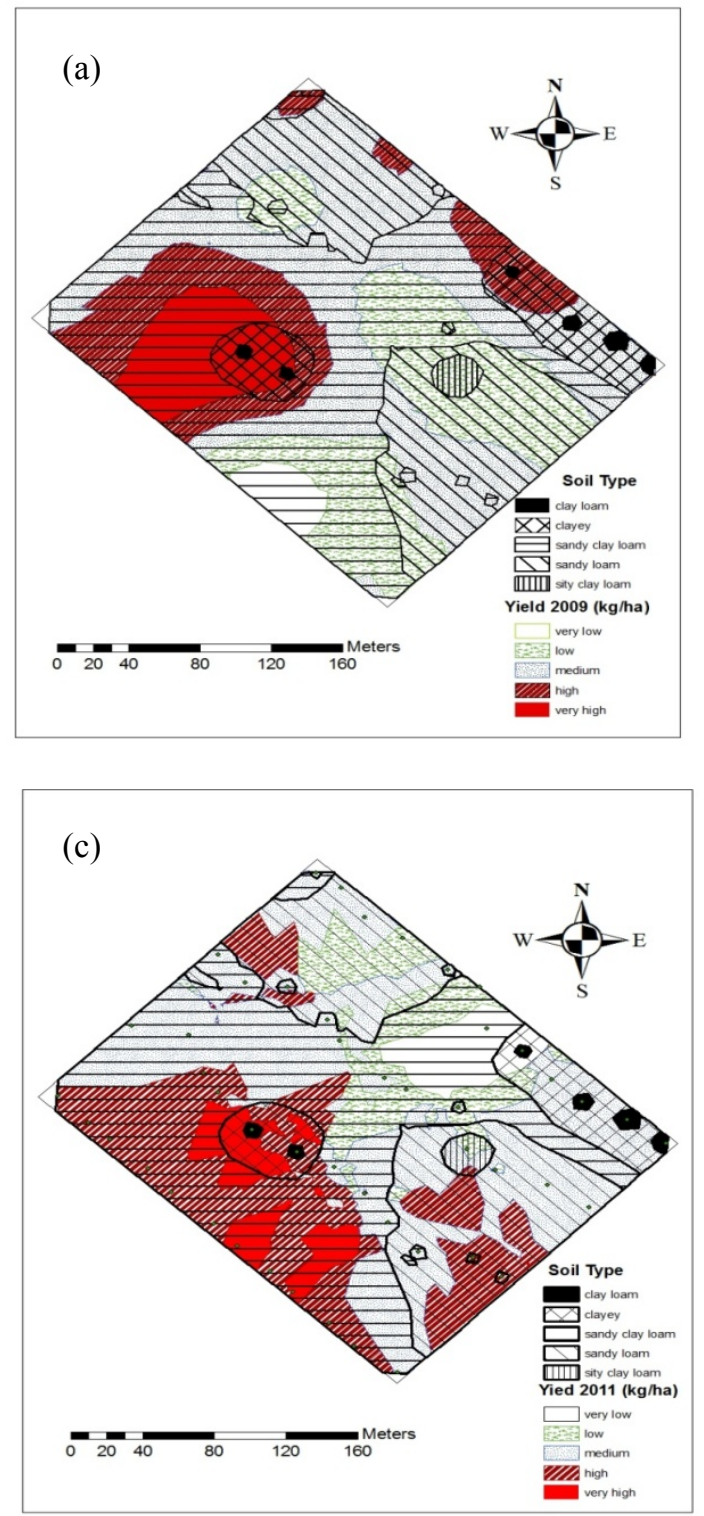

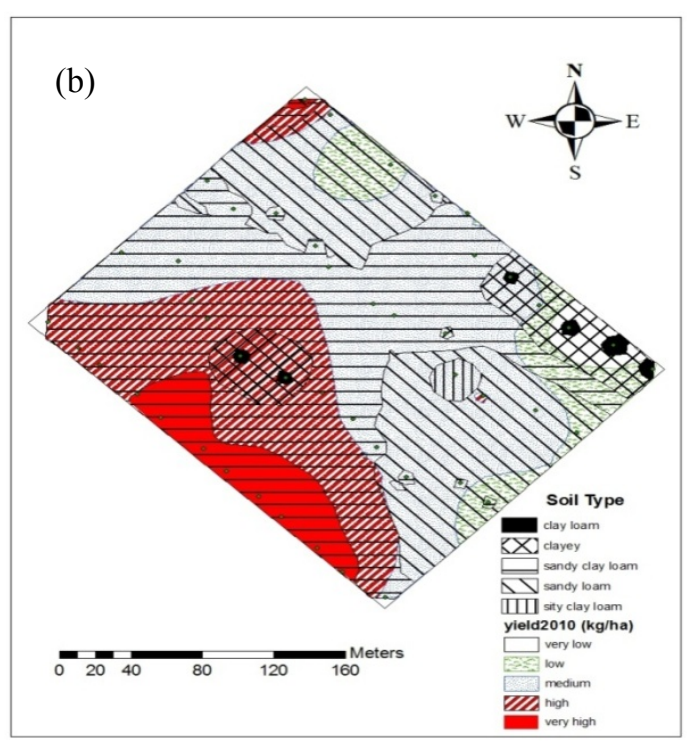

Figures 10. Map overlay for normalized yield and soil type

(a) For growing season, 2008-09

(b) For growing season, 2009-10

(c) For growing season, 2010-11 

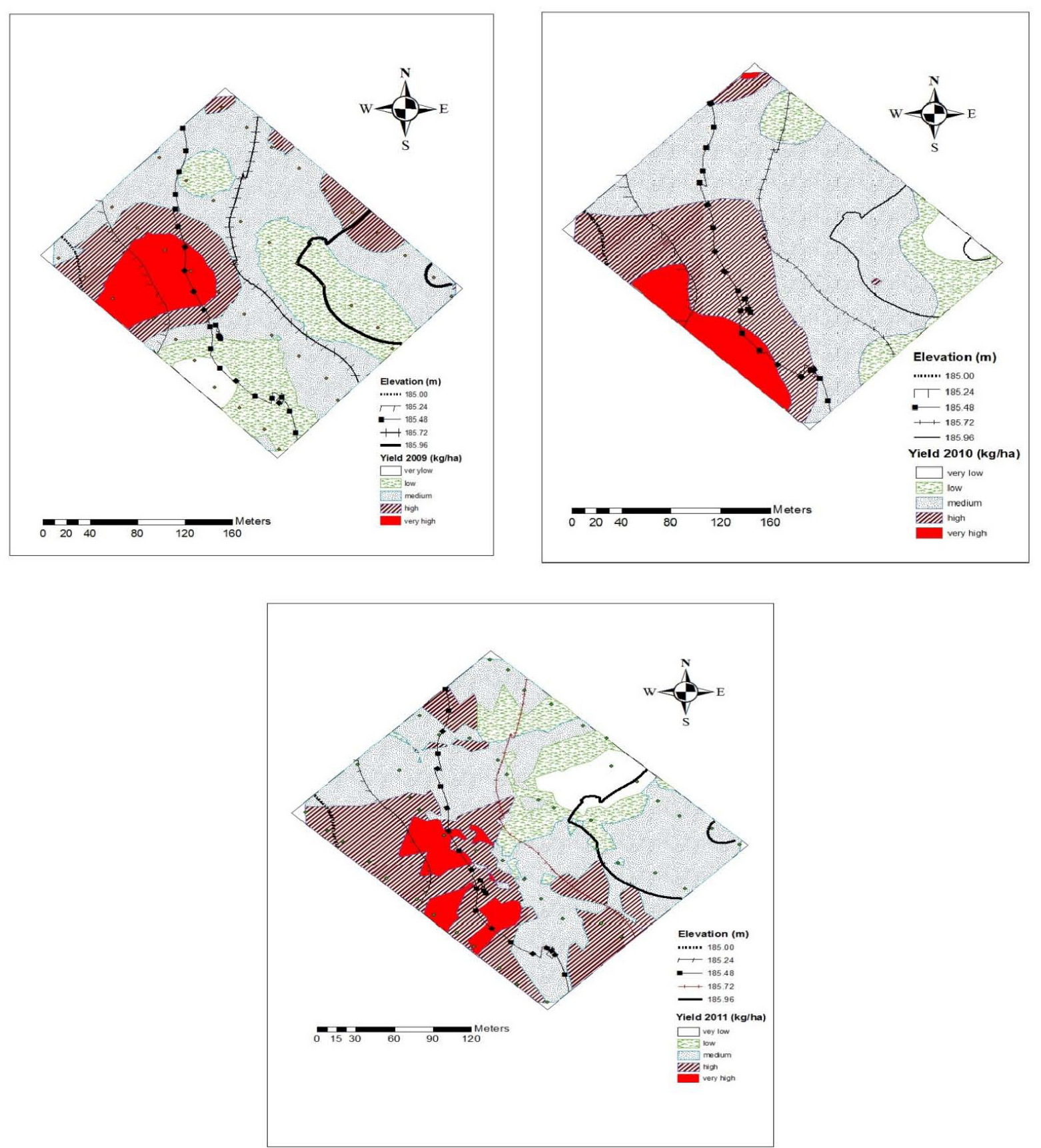

Figures 11. Map overlay for normalized yield and elevation

(a) For growing season, 2008-09; (b) For growing season, 2009-10; (c) For growing season, 2010-11 

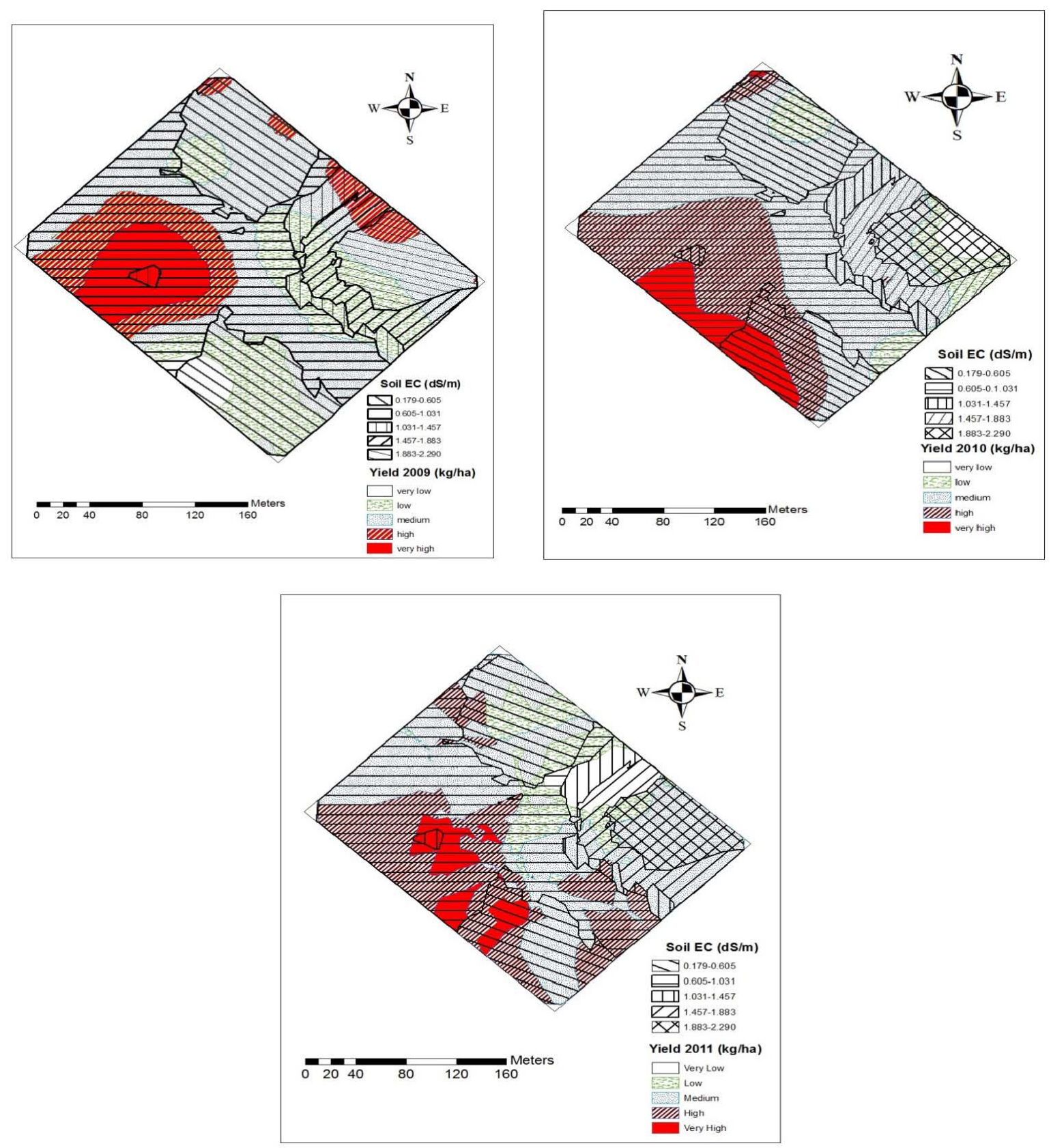

Figures 12. Map overlay for normalized yield and soil EC

(a) For growing season, 2008-09; (b) For growing season, 2009-10; (c) For growing season, 2010-11 

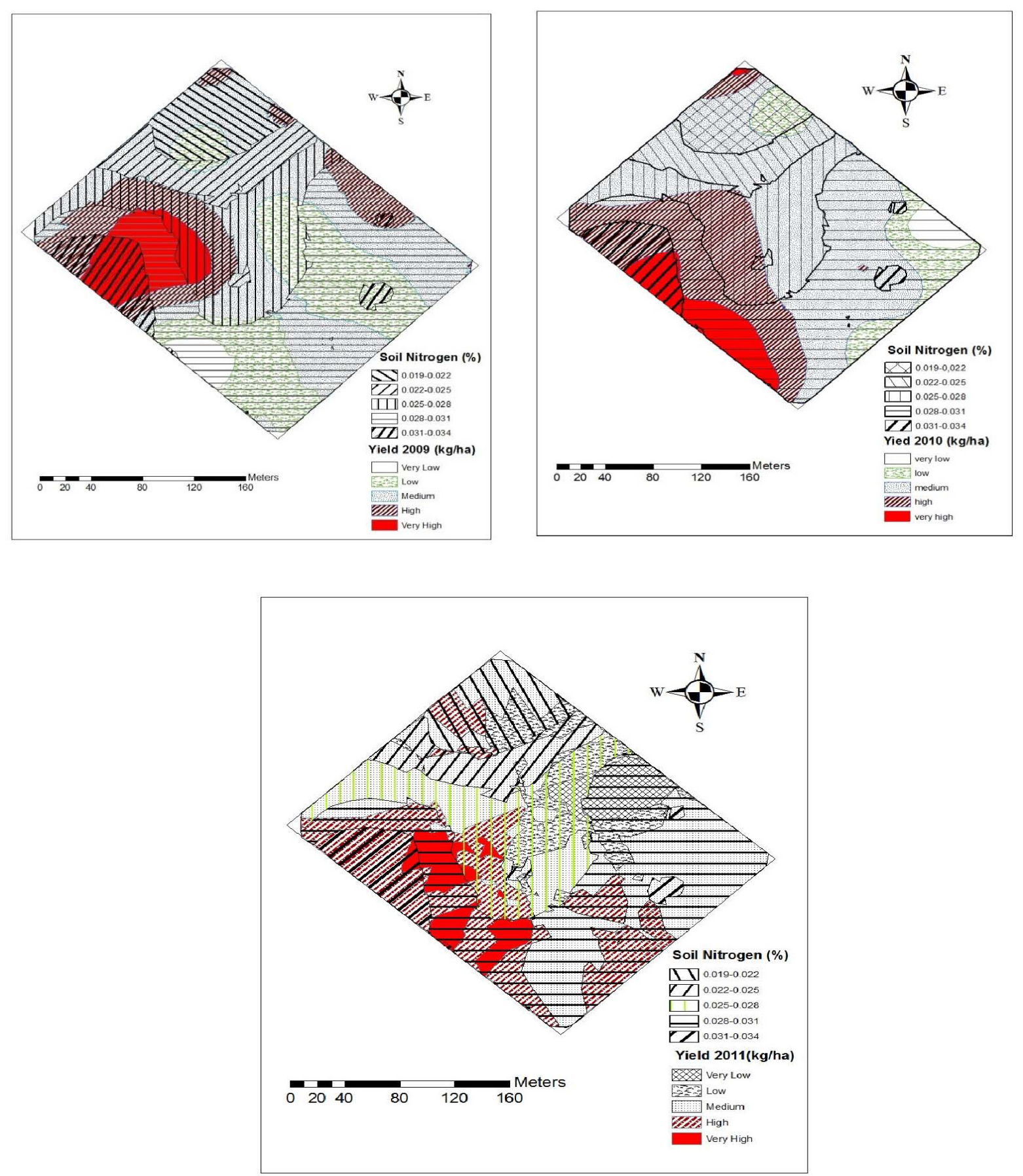

Figures 13. Map overlay for normalized yield and soil nitrogen

(a) For growing season, 2008-09; (b) For growing season, 2009-10; (c) For growing season, 2010-11 


\section{Conclusions}

Based on statistical analysis, neural network results and map overlay analysis of the yield data and landscape attributes, following conclusions are drawn:

The neural network analysis identified the fertilizer treatments as the most influencing parameter and further showed influence of the landscape attributes ranked in the order of sand, silt, clay, elevation, soil nitrogen, soil EC.

Map overlay analysis showed that areas having higher yields were relatively consistent over the years compared with the areas having lower yields. The areas having higher yields, however, were influenced by the integrated effects of lower elevation, lower soil EC, and higher soil nitrogen contents.

These results indicate that the analysis carried out using ANN and GIS approaches, proved to be a useful approach to find the most influencing parameters affecting wheat yield. The map overlay analysis, however, helped in understanding the spatial distribution of the yield pattern and their consistency over the years. The spatial analysis showed that areas having lower elevations; lower soil EC values and higher soil nitrogen contents produced higher yields. This approach can be used to establish cause-effect relationships for adopting precision agriculture.

\section{Acknowledgements}

The authors wish to express their sincere thanks to Pakistan Science Foundation (Project No. PSF/Res/P-AU/Engg.53) for providing financial assistance and the University of Agriculture, Faisalabad, Pakistan, for their cooperation and assistance, to facilitate the field experimental work at the Postgraduate Agricultural Research Station, Faisalabad, Pakistan.

\section{References}

Abbas, M., Sheikh, A. D., Sabir, H. M., \& Nighat, S. (2005). Factors responsible for low wheat productivity in Central Punjab. Pakistan Journal Agricultural Sciences, 42, 3-4. Retrieved from http://pakjas.com.pk/papers/441.pdf

Ali, A., Rehman, F., Nasir, M., \& Ranjha, M. Z. (2011). Agricultural policy and wheat production: a case study of Pakistan. Sarhad Journal of Agriculture, 27(3), 201-211. Retrieved from http://www.aup.edu.pk/sj_pdf/agricultural\%20policy\%20and\%20wheat.PDF

Arifullah, S. A., Chishti, A. F., Zulfiqar, M., Yasmeen, G., Farid, N., \& Ahmad, I. (2009). Estimating yield potential of the major crops and its implications for Pakistan's crops sector. Sarhad Journal of Agriculture, 25(4), 611-615. Retrieved from http://www.aup.edu.pk/sj_pdf/ESTIMATING\%20YIELD\%20

ASP. (2010). Agricultural Statistics of Pakistan, 2008-09, Ministry of Food, Agriculture and Livestock, Govt. of Pakistan (pp.81-87). Retrieved from http://www.pbs.gov.pk/content/agricultural-statistics-pakistan-2010-11

Awodele, O., \& Jegede, O. (2009). Neural networks and its application in engineering. Proceedings of Informing Science \& IT Education Conference (InSITE) (pp. 83-95). Retrieved from http://proceedings.informingscience.org/InSITE2009/InSITE09p083-095Awodele542.pdf

Ayoubi, S., Zamani, S. M., \& Khormali, F. (2007). Spatial variability of some soil properties for site specific farming in northern Iran. International Journal of Plant Production, 1(2), 1735-6814. Retrieved from http://adsabs.harvard.edu/abs/2008JApSc...8.1642Y

Bakhsh, A., \& Kanwar, R. S. (2005). Spatial clusters of subsurface drainage water NO3-N Leaching losses. Journal of the American Water Resources Association, JAWRA, 41(2), 333-341. http://dx.doi.org/10.1111/j.1752-1688.2005.tb03739.x

Bakhsh, A., \& Kanwar, R. S. (2008). Soil and landscape attributes interpret subsurface drainage clusters. Australian Journal of Soil Research, 46(8), 735-744. http://dx.doi.org/10.1071/SR08065

Bakhsh, A., Jaynes, D. B., Colvin, T. S., \& Kanwar, R. S. (2000). Spatio-temporal analysis of yield variability for a corn-soybean field in Iowa. Transactions of the ASAE, 43(1), 31-38. Retrieved from http://naldc.nal.usda.gov/download/27077/PDF

Bakhsh, A., Kanwar, R. S., \& Malone, R. W. (2007). Role of landscape and hydrologic attributes in developing and interpreting yield clusters. Geoderma, 140(3), 235-246. http://dx.doi.org/10.1071/SR08065

Begue, A., Lebourgeois, V., Bappe, E., Todoroff, P., Pellegrino, A., Baillarin, F., \& Siegmund, B. (2010). Spatio-temporal variability of sugarcane fields and recommendations for yield forecast using NDVI. International Journal of Remote Sensing, 31(20), 5391-5407. http://dx.doi.org/10.1080/01431160903349057 
Behera, S. K., \& Panda, R. K. (2009). Integrated management of irrigation water and fertilizers for wheat crop using field experiments and simulation modeling. Agricultural Water Management, 96(11), 1532-1540. http://dx.doi.org/10.1016/j.agwat.2009.06.016

Bernard, K. B., \& Yakubu, I. (2010). Predicting the yield of crops using GIS/GPS integration-a case study at Benso oil palm plantation limited. European Journal of Scientific Research, 42(2), 314-325. Retrieved from http://www.eurojournals.com/ejsr_42_2_14.pdf

Cemek, B., Guler, M., Kilic, K., Demir, Y., \& Arslan, H. (2007). Assessment of spatial variability in some soil properties as related to soil salinity and alkalinity in Bafra plain in northern Turkey. Environment Monitoring and Assessment, 124, 223-234. http://dx.doi.org/10.1007/s10661-006-9220-y

Colvin, T. S., Jaynes, D. B., Karlen, D. L., Laird, D. A., \& Ambuel, J. R. (1997). Yield variability within a central Iowa field. Transactions of the ASAE, 40(4), 883-889. Retrieved from http://cat.inist.fr/?aModele $=$ afficheN\&cpsidt $=2059195$

Dai, X., Huo, Z., \& Wang, H. (2011). Simulation for response of crop yield to soil moisture and salinity with artificial neural network. Field Crops Research 121, 441-449. http://dx.doi.org/10.1016/j.fcr.2011.01.016

Diaz, D. R., Hernandez, J. E. G., \& Loague, K. (1998). Leaching potentials of four pesticides used for bananas in the canary islands. Journal of Environmental Quality, 27(3), 562-572. http://dx.doi.org/10.2134/jeq1998.00472425002700030013x

Dinaburga, G., Lapins, D., Berzins, A., Kopmanis, J., \& Plume, A. (2010). Interconnection of altitude of stationary GPS observation points and soil moisture with formation of winter wheat grain yield. Agronomy Research, 8(Special Issue II), 403-408. Retrieved from http://agronomy.emu.ee/vol08Spec2/p08s216.pdf

Duffera, M., White, J. G., \& Weisz, R. (2007). Spatial variability of southeastern us coastal plain soil physical properties: implications of site specific management. Geoderma, 137(3-4), 327-339. http://dx.doi.org/10.1016/j.geoderma.2006.08.018

Farooq, A. (2010). Development of Prediction systems using artificial neural networks for Intelligent spinning machines. Ph.D. Thesis, 32-34 pp. Institute of Textile Machinery and High Performance Material Technology, Technische University Dresden, Germany. Retrieved from http://www.qucosa.de/fileadmin/data/qucosa/documents/3780/PhD\%20Thesis_Final_Farooq.pdf

Farooq, A., \& Cherif, C. (2008). Use of Artificial Neural Networks for Determining the Leveling Action Point at the Auto-leveling Draw Frame. Textile Research Journal, 78, 502-509. http://dx.doi.org/10.1177/0040517507087677

Gokalp, Z., Basaran, M., Uzun, O., \& Serin, Y. (2010). Spatial analysis of some physical soil properties in a saline and alkaline grassland soil of Kayseri, Turkey. African Journal of Agricultural Research, 5(10), 1127-1137. Retrieved http://www.academicjournals.org/ajar/pdf/pdf\%202010/18\%20May/Gokalp\%20et\%20al.pdf

GOP. (2012). Pakistan Economic Survey. Govt. of Pakistan, Finance Division, Economic Advisor's Wing, Islamabad. Retrieved from http://www.finance.gov.pk/survey/chapter_12/highlights.pdf

Haddad, F., Hagel, K., Mdeiwayeh, N., Natowitz, J. B., Wada, R., Xiao, B., ... Aichelin, J. (1997). Impact parameter determination in experimental analysis using neural network. Physical Review C (Nuclear Physics), 55(3), 1371-1375. http://dx.doi.org/10.1103/PhysRevC.55.1371

Hashmi, M. A., Garcia, L. A., \& Fontane, D. G. (1995). Spatial estimation of regional crop evapotranspiration. Transactions of the ASAE, 38(5), 1345-1351. http://cat.inist.fr/?aModele=afficheN\&cpsidt=3703966

Iqbal, J., Thomasson, J. A., Jenkins, J. N., Owens, P. R., \& Whisler, F. D. (2005). Spatial variability analysis of soil physical properties of alluvial. Soil Sciences Society of America Journal, 69, 1338-1350. http://dx.doi.org/10.2136/sssaj2004.0154

Jaynes, D. B., \& Colvin, T. S. (1997). Spatiotemporal variability of corn and soybean yield. Agronomy Journal, 89(1), 30-37. http://dx.doi.org/10.2134/agronj1997.00021962008900010005x

Jaynes, D. B., \& Hunsaker, D. J. (1989). Spatial and temporal variability of water content and infiltration on a flood irrigated field. Transactions of the ASAE, 32(4), 1229-1238. Retrieved from https://www.soils.org/publications/sssaj/abstracts/69/4/1338 
Jaynes, D. B., Colvin, T. S., \& Kaspar, T. C. (2005). Identifying potential soybean management zones from multi-year yield data. Computer and Electronics in Agriculture, 46, 309-327. http://dx.doi.org/10.1016/j.compag.2004.11.011

Jung, W. K., Kitchen, N. R., Sudduth, K. A., \& Anderson, S. H. (2006). Spatial characteristics of claypan soil properties in an agricultural field. Soil Sciences Society of America Journal, 70, 1387-1397. http://dx.doi.org/10.2136/sssaj2005.0273

Khazaei, J., Shahbazi, F., Massah, J., Nikrvesh, M., \& Kianmehr, M. H. (2008). Evaluation and modeling of physical and physiological damage to wheat seeds under successive impact loadings: Mathematical and neural networks modeling. Crop Sciences, 48(4), 1532-1544. http://dx.doi.org/10.2135/cropsci2007.04.0187

Kobayashi, H., Park, B. J., \& Miyazaki, Y. (2012). Normative references of heart rate variability and salivary alpha-amylase in a healthy young male population. Journal of Physiological Anthropology, 31(9), 1-8. Retrieved from http://www.jphysiolanthropol.com/content/31/1/9

Lashin, A., \& Din, S. S. E. (2012). Reservoir parameters determination using artificial neural networks: Ras Fanar field, Gulf of Suez, Egypt. Arabian Journal of Geosciences. http://dx.doi.org/0.1007/s12517-012-0541-6

Lithourgidis, A. S., Damalas, C. A., \& Gagianas, A. A. (2006). Long-term yield patterns for continuous winter wheat cropping in northern Greece. European Journal of Agronomy, 25, 208-214. http://dx.doi.org/10.1016/j.eja.2006.05.003

Lund, E. D., Colin, D. C., \& Paul, E. D. (2000). Using yield and soil electrical conductivity (EC) maps to derive crop production performance information. Presented at the 5th International Conference on Precision AgricultureVeris Technologies Salina KS, (785) 825-1978. Retrieved from http://www.veristech.com/images/ecfaq/EC_yld_analysis\%20paper_5thconf.pdf

Marques, D. S. J. R., \& Silva, L. L. (2008). Evaluation of maize yield spatial variability based on field flow density. Biosystems Engineering, 101(2), 183-190. http://dx.doi.org/10.1016/j.biosystemseng.2006.06.015

Mulla, D. J., \& Schepers, J. S. (1997). Key processes and properties for site-specific soil and crop management. In Proc. The State of Site Specific Management for Agriculture, 1-18. Madison, Wis.: ASA/CSSA/SSSA. Retrieved from http://www.cabdirect.org/abstracts/19971910728.html

Noble, P. A., \& Tribou, E. H. (2007). Neuroet: An easy-to-use artificial neural network for ecological and biological modeling. Ecological Modeling, 203, 87-98. http://dx.doi.org/10.1016/j.ecolmodel.2005.06.013

Noori, S. S. A., Ebrahimi, M., Khazaei, J., \& khalaj, H. (2011). Predicting yield of wheat genotypes at different salinity by artificial neural network. African Journal of Agricultural Research, 6(12), 2660-2675. http://dx.doi.org/10.5897/AJAR09.555

Nouri, H., Amin, M. S. M., Razavi, S. J., Anuar, A. R., \& Aimrun, W. (2009). Precision Agriculture Concept: Distribution Pattern of Selected Soil and Crop Characteristics Influenced by Fertigation. European Journal of Scientific Research, 32(2), 231-240. Retrieved from http://agrardienst.synersys.org/?p=117

Parent, A. C., Belanger, M. C., \& Santerre, R. (2008). Soil properties and landscape factors affecting maize yield under wet spring conditions in eastern Canada. Biosystems Engineering, 99(1), 134-144. http://dx.doi.org/10.1016/j.biosystemseng.2007.10.006

Piotrowska, A., Dlugosz, J., Wilczynsk, B. N., \& Zamorski, R. (2011). Field-scale variability of topsoil dehydrogenase and cellulase activities as affected by variability of some physico-chemical properties. Biology and Fertility of Soils, 47, 101-109. http://dx.doi.org/10.1007/s00374-010-0507-3

Samarasinghe, S. (2007). Neural Networks for Applied Sciences and Engineering: from Fundamentals to Complex Pattern Recognition. Auerbach, 2007. Retrieved from http://www.crcnetbase.com/isbn/9781420013061

Sinclair, T. R., \& Seligman, N. G. (1996). Crop modeling: from infancy to maturity. Agronomy Journal, 88(5), 698-704. http://dx.doi.org/10.2134/agronj1996.00021962008800050004x

Solaimani, K. (2009). Rainfall-Runoff Prediction Based on Artificial Neural Network (A Case Study): Jarahi Watershed). Journal of Agriculture \& Environmental Sciences, 5(6), 856-865. Retrieved from http://idosi.org/aejaes/jaes5(6)/20.pdf

Srinivasa, L. P. E., \& Brion, G. M. (2005). Artificial Neural Networks in Water Spatial variability of measured soil properties across site-specific management zones. Soil Sci. Soc. Am. J., 69, 1572-1579. http://dx.doi.org/10.2136/sssaj2005.0062 
Tran, B. Q., \& Nguyen, T. T. (2008). Assessment of the influence of interpolation techniques on the accuracy of digital elevation model. VNU Journal of Science, Earth Sciences, 24, 176-183. Retrieved from http://hdl.handle.net/123456789/279

Yang, C., Peterson, C. L., Shropshire, G. J., \& Otawa, T. (1998). Spatial variability of field topography and wheat yield in the palouse region of the Pacific Northwest. Transactions of the ASAE, 41(1), 17-27. Retrieved from http://cat.inist.fr/?aModele=afficheN\&cpsidt=2197788

Zaman, Q., \& Schumann, A. W. (2006). Nutrient management zones for citrus based on variation in soil properties and tree performance. Precision Agriculture, 7, 45-63. http://dx.doi.org/10.1007/s11119-005-6789-z

Zhai, Y., Thomasson, J. A., Boggess, J. E., \& Sui, R. (2010). Soil texture classification with artificial neural networks operating on remote sensing data. Computers and Electronics in Agriculture, 54, 53-68. http://dx.doi.org/10.1016/j.compag.2006.08.001 